\title{
REMEMBERING MALCOLM
}

I knew Malcolm's name for far longer than our relatively brief period of work together. I was first introduced to him by David Drew, who enthusiastically sang Malcolm's praises. At Bridge Records, my wife Becky and I were always on the hunt for perceptive writers on music, especially those who wrote about the new or rarely performed. Malcolm fit that bill perfectly, and the result was a steady stream of oft-praised essays. Here was a writer who got to the core of what made a particular composer or composition unique. It didn't seem to matter whether it was Mozart, Carter, Schumann or Ruders, Malcolm's writing glorified the detail and inspiration that separated his subject from the norm. He quickly became our most valued annotator. About two weeks before he died I asked him to write about Haydn piano sonatas and concertos. Although he was suffering through the ordeals of late stage cancer therapy, he agreed to the project without a moment's hesitation. I like to think that in his last hours, alongside the love of his dear Libby, there was beautiful music - imagined, heard and supremely understood.

David Starobin 


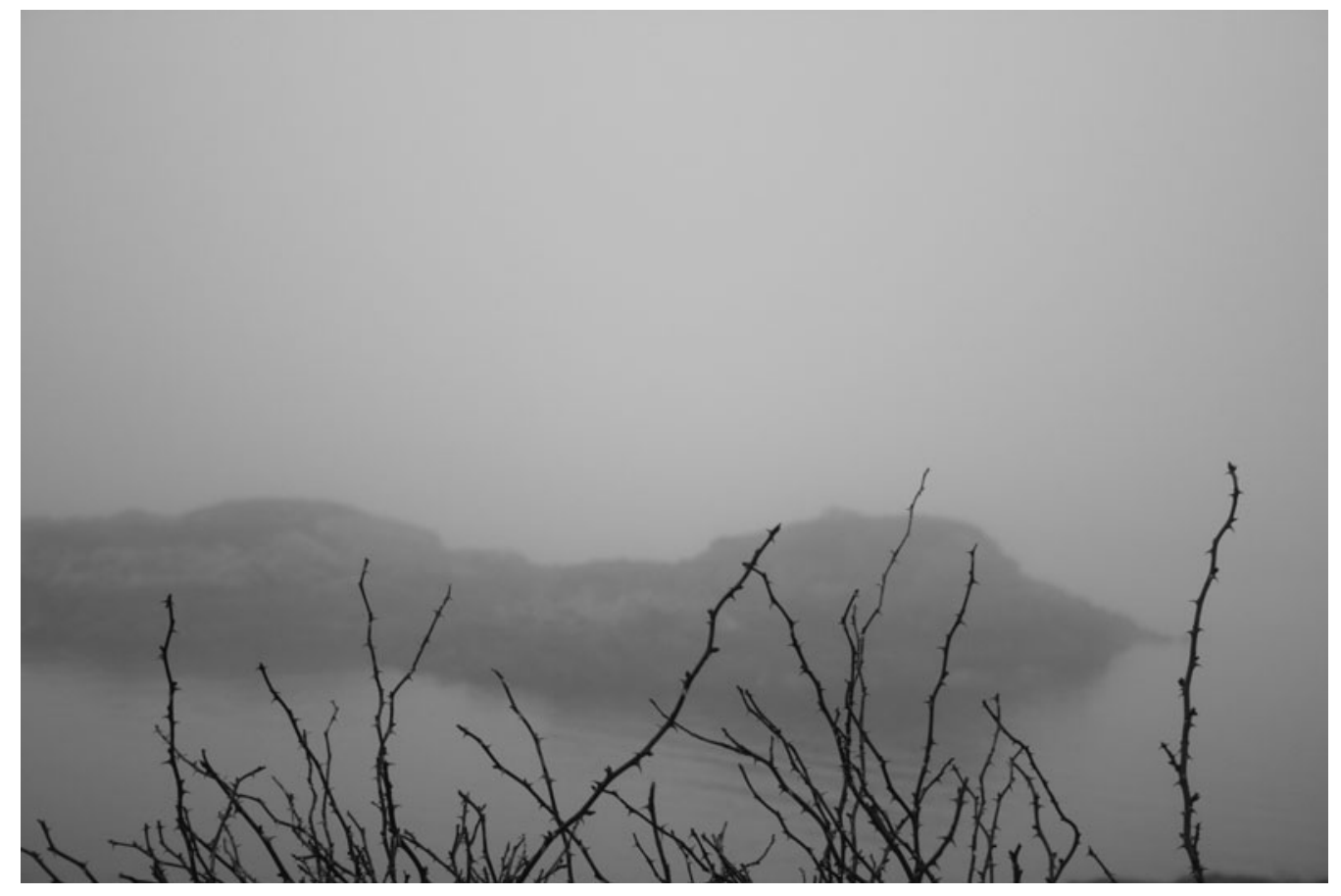

(C) 2010 Piers Hellawell, the aird in mist, black and white print 